\title{
STUDY OF THE CLINICAL AND LABORATORY PROFILE OF PATIENTS WITH SYSTEMIC LUPUS ERYTHESUS IN A UNIVERSITY HOSPITAL IN TAUBATÉ
}

Elisa Fernandes de Melo ${ }^{1}$, Raylane Shellyda de Almeida Anate ${ }^{1, \star}$, Ana Clara Liz da Silva Cunha ${ }^{1}$, Jessica Louise de Godoi Pierini ${ }^{1}$, Thais Gonçalves dos Santos ${ }^{1}$, Isabel Penteado Sitolini ${ }^{1}$, Marina Fernandez Florençano ${ }^{1}$

1.Universidade de Taubaté, Taubaté (SP), Brazil.

*Corresponding author: raymed87@gmail.com

\section{BACKGROUND}

Perform a retrospective study of the clinical and laboratory manifestations of patients diagnosed with systemic lupus erythematosus (SLE) treated at a University Hospital in the city of Taubaté, São Paulo.

\section{MATERIALS AND METHODS}

The medical records of 26 patients from the rheumatology outpatient clinic from 2018 to 2020 were reviewed, being statistically analyzed for comparison with the literature. The clinical and laboratory characteristics analyzed are based on epidemiology, diagnostic criteria of the American College of Rheumatology (EULAR/ACR 2019) and other antibodies present.

\section{RESULTS}

Of the 26 patients analyzed, the majority were female ( $88.5 \%)$, with predominance between 20 and 45 years. The most frequent SLE criteria were positive ANA (88.5\%) and joint disorder (88.5\%), followed by skin manifestations (65.4\%).

\section{CONCLUSION}

In the population studied, cases of SLE were characteristic of young women, with ANA positivity, joint disorder and cutaneous manifestations being the most frequent criteria, demonstrating agreement with the literature. Therefore, the identification of the typical clinical characteristics of the region contributes to greater diagnostic efficiency and patient care.

\section{REFERENCES}

1. La Paglia GMC, Leone MC, Lepri G, Vagelli R, Valentini E, Alunno A, et al. One year in review 2017: systemic lupus erythematosus. Clin Exp Rheumatol. 2017;35(4):551-61.

2. Wallace MD, Gladman DD. Clinical manifestations and diagnosis of systemic lupus erythematosus in adults. UpToDate [Internet]. 2019 [cited 2020 Apr 14]. Available from: https://www.uptodate.com/contents/clinical-and-diagnosis-of-systemic-lupus-erythematosus-in-adults 